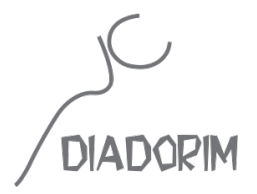

\title{
GRAMÁTICA E ENSINO
}

GRAMMAR AND TEACHING

\author{
Carlos Alberto Faraco
}

\section{RESUMO}

Neste artigo, fazemos uma breve revisão histórica do ensino de gramática desde a Antiguidade Clássica. Na sequência, recuperamos as características do ensino de gramática na tradição escolar luso-brasileira e resenhamos algumas das principais propostas alternativas ao modelo tradicional formuladas, nas últimas décadas, por linguistas brasileiros que têm se envolvido com o ensino de língua portuguesa. Seguimos, portanto, uma metodologia historiográfica e, na parte final, damos destaque a questões que precisam ser melhor detalhadas nas propostas alternativas.

PALAVRAS-CHAVE: gramática, ensino de gramática, aspectos históricos.

\section{ABSTRACT}

In this article, we present a brief history of the teaching of grammar since the Classical Antiquity. Afterwards, we revisit the main characteristics of the teaching of grammar in the Luso-Brazilian school tradition and we review some of the main alternative proposals to the traditional model formulated in the last decades by Brazilian linguists that have been involved with the teaching of Portuguese. We follow a historiographic methodology and, in the end of the text, we give attention to points that need to be better detailed in the alternative proposals.

KEYWORDS: grammar, teaching of grammar, historical aspects.

\section{I.}

Escola e gramática caminham juntas há milênios. No currículo medieval, a gramática era uma das disciplinas do trivium, ao lado da lógica e da retórica. E estava no trivium como herança das concepções teóricas e pedagógicas desenvolvidas pelo mundo greco-romano.

A simbiose escola/gramática remonta aos gregos alexandrinos. Foram eles que criaram, por volta do século II a.C., a gramática como disciplina autônoma, paralelamente a seus estudos de filologia, que se voltavam para a edição crítica dos textos de autores gregos clássicos. A gramática nasceu, portanto, da filologia, absorveu um conceitual filosófico (por exemplo, as classes dos 
nomes e dos verbos; e as noções de sujeito e predicado) e, posteriormente, incorporou capítulos com conteúdos retirados da retórica (as chamadas figuras de linguagem).

A primeira gramática que conhecemos - a Tékhne Grammatiké - tem sua autoria atribuída a Dionísio Trácio (170 a.C. - 90 a.C.), de cuja vida pouco se sabe. Acredita-se que tenha sido aluno e seguidor de Aristarco da Samotrácia (215 a.C. - 145 a.C.) em Alexandria e tenha se dedicado aos estudos dos textos de Homero.

Essa primeira gramática lançou as bases de um modelo de descrição organizado em dois grandes eixos: as classes de palavras e a sintaxe da sentença. Delimitou, para essa descrição, uma nomenclatura e fixou, pela variedade linguística de referência (o uso dos poetas e prosadores), um viés normativo.

Tal modelo - a que Francisco Eduardo Vieira (2015 e 2016) dá o sugestivo nome de Paradigma Tradicional de Gramatização - vem se reproduzindo desde então e formata ainda hoje as chamadas gramáticas tradicionais.

Como nos mostra Maria Helena de Moura Neves (1987), em seu amplo estudo das raízes gregas dessas gramáticas, a cultura helenística vivia, por volta do século II a.C., um momento de conflitos culturais em meio aos quais era sentida uma ameaça de sobrepujamento da língua grega pelos falares "bárbaros" (ou seja, não gregos). Essa conjuntura de crise foi determinante para o desenho da atenção que os eruditos alexandrinos davam aos textos gregos clássicos (aos de Homero, sobretudo) não só para preservá-los, mas também para descrever a variedade da língua que ocorria nesses textos e que, em contraste com o grego corrente na época helenística, era assumida como a mais pura justamente por ter sido o veículo de expressão dos grandes poetas e prosadores do passado. Deveria, portanto, ser tomada como modelo.

Nessas circunstâncias, diz Neves (2006: 33), a gramática só poderia nascer modelar. Descrevia quadros paradigmáticos sem um discurso diretamente prescritivo. No entanto, ao excluir outros, tais quadros funcionavam, de fato, normativamente, o que ficava reforçado pelo caráter exemplar das amostras retiradas dos textos tidos como representativos da "boa" linguagem.

Assim, embora não tivesse um discurso prescritivo explícito, a gramática, por ser, nas palavras da Tékhne Grammatiké, “o conhecimento empírico do comumente usado (dito) por poetas e prosadores" (cf. CHAPANSKI, 2003), nascia necessariamente normativa e tinha como objeto fundamental a língua escrita conforme praticada pelos grandes escritores do passado.

Entendida como "arte", ou seja, como um saber prático, a gramática era considerada o instrumento para o aprendizado da variedade assumida como modelar. Não a gramática em si, tomada isoladamente, mas combinada com a leitura, o estudo e o comentário dos textos dos poetas e prosadores culturalmente prestigiados, como deixou registrado Marco Fábio Quintiliano (30 d.C. - 96 d.C.) no seu tratado Institutio Oratoria, escrito no ano de 95 da nossa era, obra que sintetizou e consolidou as linhas mestras da educação linguística greco-romana. ${ }^{1}$

\footnotetext{
1 O livro de Quintiliano foi recentemente traduzido para o português por Bruno F. Bassetto e publicado pela Editora da Unicamp (Instituição oratória. Tomos I a IV. Campinas: Editora da Unicamp, 2015 e 2016). Aqui, estou tomando como referência a tradução do livro I, feita por Pereira (2005).
} 


\section{II.}

Por Quintiliano, ficamos sabendo (Livro I, cap. IV) que essa educação tinha três estágios: no primeiro, as crianças aprendiam a ler e escrever; em seguida, iam para a classe do grammaticus, professor cuja tarefa era ensinar a gramática e, ao mesmo tempo, ler e comentar com os alunos os textos dos autores assumidos como modelares, fazendo-os exercitar a expressão pela imitação desses autores; por último, os alunos passavam a frequentar as aulas do rethor, que lhes ensinava a retórica.

A meta superior de todo esse processo educacional era formar o bom orador. A etapa do grammaticus era vista como preparatória, complementar, auxiliar ao que, de fato, importava: alcançar o domínio dos fundamentos e das práticas retóricas.

Sobre especificamente o trabalho do grammaticus, Quintiliano recomendava que, nos estudos gramaticais, não se descesse a minúcias fastidiosas, pois, concluía ele, "nada do que diz respeito à gramática fará mal, salvo o que é inútil” (Livro I, cap. VII, 34). Ou seja, Quintiliano postulava uma diretriz pedagógica claramente funcional: não ensinar a gramática em si, mas sempre articulada à leitura e comentários dos textos exemplares e à produção dos alunos; e não descer a detalhes, mas selecionar o que, de fato, pode ser útil para o domínio da expressão - expressão que Quintiliano considerava devesse ter três virtudes, "quais sejam, a correção, a clareza e a elegância" (Livro I, cap. V, 1), embora, mais à frente, ele afirmasse que a clareza é a maior das virtudes do discurso (Livro I, cap. VI, 4). ${ }^{2}$

\section{III.}

Essa concepção perdeu, com o passar do tempo, boa parte de sua vitalidade e a gramática deixou de ser vista como disciplina complementar, auxiliar e funcional e passou a ocupar um lugar central na educação linguística.

Essa mudança foi consequência das progressivas alterações do panorama sociolinguístico da Europa ocidental depois do fim do império romano do Ocidente. Com a quebra da unidade política, foram adquirindo autonomia, na comunicação cotidiana, os falares românicos (que se constituíram em decorrência das divergentes evoluções do latim falado - o chamado latim vulgar - nas diferentes regiões do antigo império). Ao mesmo tempo, o chamado latim clássico foi se especializando como a língua da erudição. Seus aprendizes e cultores não eram mais falantes nativos da variedade culta da língua, do chamado sermo urbanus (porque já não havia mais esses falantes); e a referência para seu domínio era exclusivamente a língua escrita em textos dos autores latinos consagrados e as propriedades morfossintáticas fixadas nas gramáticas.

A educação linguística não era mais pautada pelo aprimoramento da língua de casa (como tinha

\footnotetext{
2 É interessante dar destaque neste ponto ao fato de que Quintiliano já propunha, para o aperfeiçoamento da expressão escrita, a refacção dos textos pelo aluno, conforme se pode ler no livro II, cap. IV, 13, onde ele diz: "Se o texto é ruim, percebi que é útil que o aluno reescreva depois de ter o texto analisado junto comigo e ele estimulado a fazer ainda melhor".
} 
sido na Roma de Quintiliano), mas pela necessidade de aprender a língua da erudição a partir do zero. Foi por aí que o conhecimento gramatical deixou de ser apenas complementar e passou a primordial.

Essa pedagogia medieval que, em razão das mudanças históricas, teve de pôr a gramática no centro do ensino apareceu sintetizada na Ratio Studiorum, documento que, publicado em 1599, consolidou as diretrizes educacionais para os inúmeros colégios dos jesuítas na Europa e fora dela (cf. The jesuit Ratio Studiorum of 1599).

Essa ordem religiosa tinha sido fundada em 1540 e, no contexto da chamada Contrarreforma, passou a ser a principal responsável pela educação na Europa católica e nos seus domínios coloniais na América e na Ásia do século XVI até a metade do XVIII, quando foi suprimida pelo Papa depois de sucessivos conflitos políticos entre os jesuítas e as autoridades governamentais de vários países.

A Ratio Studiorum previa, inspirada no pensamento de Quintiliano, um amplo programa focado nas artes liberais (gramática e retórica em particular). Destacava a importância das atividades de leitura, escrita e oralidade, mas, tendo a gramática latina do jesuíta português Manuel Alvares (1526-1583) - De institutione grammatica libri tres, publicada em 1572 - como o manual de referência, detalhava extensamente os programas das classes de gramática, divididas em três estágios - elementares, médias e superiores. ${ }^{3}$

A Ratio determinava também que todo o ensino fosse em latim, devendo os alunos, no colégio, usar apenas essa língua. ${ }^{4}$ Em decorrência, pressupunha-se o mais completo e perfeito conhecimento da gramática do latim clássico. ${ }^{5} \mathrm{Na}$ regra 3 para os professores das classes elementares de gramática, lê-se ainda: "o professor deve ter a correção gramatical como seu padrão de julgamento". Assim, por mais recheado que fosse o currículo escolar de outras atividades, o centro era, de fato, o ensino de gramática - a exposição e exemplificação da nomenclatura e a apresentação dos paradigmas morfológicos.

Havia também uma proibição explícita quanto ao uso da língua materna dos alunos no ensino. ${ }^{6}$ Ela só poderia ocorrer excepcionalmente, restrita a um uso puramente instrumental como, por exemplo, num breve resumo do texto que se iria estudar, o que era aceitável apenas com os alunos das primeiras classes pelo fato de que ainda não sabiam suficientemente o latim.

\section{IV.}

Uma perspectiva radicalmente diferente foi formulada por Jan Comênio (1592-1670), autor de Didática Magna, livro que foi publicado em 1627 em tcheco e em 1631 em latim, e é considerado o primeiro tratado pedagógico moderno.

Comênio estava vinculado ao movimento da Reforma religiosa que, desde o século anterior, defendia, entre outras teses, a tradução da Bíblia para as línguas vernáculas com o objetivo de

\footnotetext{
Cf. a regra 8, 2 das regras para o prefeito dos estudos menores.

Cf. a regra 8 das regras comuns para os professores das classes menores.

Cf. a regra 1 para os professores das classes superiores de gramática.

Cf. a regra 8 das regras comuns para os professores das classes menores.
} 
permitir a todos os crentes o acesso direto ao texto.

Essa atitude resultou na valorização das línguas vernáculas na Europa protestante e repercutiu na proposta educacional de Comênio. Ele foi dos primeiros a defender que a educação fundamental fosse feita na língua materna dos alunos e não mais em latim (cf. cap. XXIX). Este deveria ser ensinado apenas nas séries finais da educação secundária.

Especificamente quanto à pedagogia da língua materna, Comênio dizia que as línguas devem ser aprendidas mais com a prática do que por meio de regras (cf. cap. XXII, 11) e acrescentava: "não aprender nenhuma língua a partir da gramática, mas a partir dos autores apropriados" (cf. cap. XVI, 19, III).

Assim, na proposta de Comênio, voltava ao centro da educação linguística o domínio das práticas de leitura, de escrita e de oralidade. E a gramática perdia seu estatuto. Comênio não dispensava totalmente a gramática como matéria de ensino, mas chegava perto disso, reduzindo seu espaço a breves regras gerais descritivas dos fatos.

Em suma, a história da educação linguística desde a Antiguidade até o século XVII deu forma a três postulações pedagógicas referentes ao ensino de gramática: seu estudo deve ser complementar e funcional (Quintiliano); seu estudo deve ocupar o centro do ensino (Ratio Studiorum); seu estudo é quase dispensável (Comênio).

\section{V.}

Ainda hoje parece que deslizamos entre essas três postulações. Há quem defenda um ensino sem gramática e voltado exclusivamente ao desenvolvimento das práticas de leitura, de escrita e de oralidade. Talvez tenham sido os linguistas Geraldo Mattos e Eurico Back os mais radicais defensores dessa tese entre nós (cf. MATTOS E BACK, 1974). Há também quem pratique um ensino centrado na gramática, embora não haja quem defenda abertamente essa centralidade, salvo, talvez, a mídia e o senso comum. Por último, os documentos oficiais mais recentes se referem sempre à gramática como um conhecimento complementar, auxiliar e articulado com a leitura $\mathrm{e}$ a produção de texto, embora não se estendam sobre como operacionalizar esse princípio geral.

Apesar dessa diretriz dos documentos oficiais, a gramática permanece nas práticas escolares em posição de destaque, o que fica evidente seja pela partição, em muitas escolas, das aulas de português em aulas de gramática, de redação e de literatura, seja principalmente pelo conteúdo dos livros didáticos do ensino fundamental e médio, que reservam um lugar privilegiado para os conteúdos gramaticais arrolados pela NGB - Nomenclatura Gramatical Brasileira e detalhados pelas gramáticas escolares (cf., por exemplo, o estudo de BAGNO, 2010).

No início da década de 1990, Maria Helena de Moura Neves fez uma enquete entre 170 professores de português do Estado de São Paulo que revelou um forte apego ao ensino de gramática (cf. NEVES, 1990). Os professores justificavam tal ensino asseverando a crença, amplamente aceita no ambiente escolar e na sociedade (embora nunca efetivamente demonstrada - cf., entre outros, BRITTO, 1997: 176-180), de que o conhecimento da metalinguagem é pré-requisito para um bom desempenho linguístico. Paradoxalmente, os mesmos professores reconheciam a pouca eficácia e utilidade de tal ensino que, contudo, continuava a ser feito até como forma de legitimação do seu papel de professores de português, o que é compreensível, considerando que, 
para o senso comum, ensinar português é ensinar gramática.

Essa equivalência de senso comum veio mais uma vez à baila recentemente quando foi publicada a primeira versão da BNCC - Base Nacional Curricular Comum. De imediato, os críticos apontaram a pouca referência à gramática como um problema grave da proposta. Na ocasião, o próprio ministro da Educação se manifestou, dizendo que tal lacuna seria devidamente "corrigida" na versão seguinte (cf. Folha de S. Paulo, Educação, 11/10/2015 - "Mercadante defende mais gramática no currículo nacional de educação").

Tudo indica, pois, que pouco ou nada mudou passados 25 anos da enquete de Maria Helena de Moura Neves. A tradição que se estabeleceu e se consolidou na nossa história educacional continua forte. Afinal, foi sob a égide da centralidade da gramática que teve início nosso sistema educacional. Sua base foi dada pelos colégios jesuítas e, portanto, pelas concepções delineadas na Ratio Studiorum.

A expulsão dos jesuítas em 1759 e as reformas da educação feitas pelo governo do marquês de Pombal (que durou de 1750 a 1777) resultaram em poucas mudanças. Trouxeram antes um desmonte do sistema que só no século XIX começou, de fato, a ser formalmente reconstituído.

No contexto das reformas pombalinas, o ensino passou a ser feito em língua materna em Portugal. No entanto, a língua portuguesa propriamente dita só se tornou disciplina escolar autônoma no Brasil e em Portugal na segunda metade do século XIX. Importante lembrar, porém, que um Alvará Real de 30 de setembro de 1770 determinou a obrigatoriedade de os professores de latim ensinarem previamente, nos seis primeiros meses de aula, a gramática portuguesa, especificamente aquela escrita por António José dos Reis Lobato e publicada naquele mesmo ano.

O Alvará justificava essa determinação, dizendo que a correção das línguas nacionais é "um dos objetos mais atendíveis para a cultura dos povos civilizados" e que não há "meio que mais possa contribuir para polir e aperfeiçoar qualquer idioma (...) do que a aplicação da mocidade ao estudo da gramática da sua própria língua”. E continuava: "Sabendo-as por princípios, e não por mero instinto e hábito, se costuma a falar e escrever com pureza, evitando aqueles erros que tanto desfiguram a nobreza do pensamento" (cf. Alvará de 30 de setembro de 1770).

O Alvará vincula, portanto, o domínio da língua ao saber gramatical ("não há meio que mais possa contribuir para polir e aperfeiçoar qualquer idioma") e o saber gramatical à correção da linguagem. Esse Alvará Real era parte do combate ao modelo educacional dos jesuítas. No entanto, mantinha, no fundo, o princípio da centralidade da gramática na educação linguística. Dava um passo no sentido de introduzir a língua portuguesa como matéria escolar, mas o fazia pelo viés redutor do ensino centrado na gramática, o que certamente contribuiu para consolidar a tradição, tão forte entre nós, que confunde ensinar português com ensinar gramática.

\section{VI.}

Essa centralidade se estendeu ao Brasil. O primeiro documento pós-independência a tratar da educação (a lei de 15/10/1827), que determinou a criação das escolas de primeiras letras no país, incluía, no seu artigo $6^{\circ}$, uma lista de tópicos que deveriam ser ensinados nestas escolas, entre os quais “a gramática da língua nacional”. Não a língua nacional, mas a gramática da língua nacional. 
Quando, em 1887, se fez a reformulação do ensino secundário, os programas de português publicados para orientar os chamados exames preparatórios (que valiam para ingresso no ensino superior) se centravam, de novo, na gramática. Esses programas estipulavam, para os exames, uma prova de redação sobre um tema sorteado e uma prova oral realizada em duas etapas: primeiro a análise fonética, morfológica e sintática de um trecho escolhido pela banca e, em seguida, uma exposição de um tema gramatical sorteado. Para esta última prova, os programas listavam 46 itens gramaticais desde os conceitos de gramática até as figuras de linguagem, passando pela fonologia, ortografia, classes de palavras, formação do léxico e sintaxe.

Esses programas de 1887 motivaram a escrita de várias gramáticas escolares que se propunham a apresentar detalhadamente cada um daqueles 46 itens. Essas primeiras gramáticas (escritas por João Ribeiro, por Alfredo Gomes, por Pacheco da Silva Jr. \& Lameira de Andrade e por Maximino Maciel) e as posteriores (em especial as de Eduardo Carlos Pereira) passaram a ser, ao lado da Antologia Nacional (cf. RAZZINI, 2000), os livros de referência do ensino de português durante boa parte do século XX. Depois de 1959, os autores das gramáticas escolares continuaram repetindo o modelo, apenas ajustando-o à NGB, que permanece balizando tanto as gramáticas escolares atuais quanto os livros didáticos.

Nas reformulações do ensino secundário nas décadas de 1930 e 1940, praticamente nada se alterou. No início da década de 1940, por exemplo, os programas de português da reforma Capanema arrolavam fundamentalmente tópicos de gramática distribuídos pelas séries dos cursos primário (as classes de palavras) e ginasial (a análise sintática), reservando a gramática histórica e a literatura para o curso colegial.

Esses programas perduraram até, pelo menos, a LDB - Lei de Diretrizes e Bases da Educação de 1961 (a lei 4.024/61), mas, por força da tradição, nunca foram, de fato, abandonados pela escola (com exceção da gramática histórica, que desapareceu do ensino básico), mesmo quando os documentos oficiais passaram a adotar um discurso diferente, recomendando um papel auxiliar ao ensino de gramática.

Esse discurso que tem estado nos documentos oficiais mais recentes ganhou espaço a partir de meados de 1980. Sua primeira grande referência foram as propostas de reformulação curricular do Estado de São Paulo, elaboradas por linguistas da UNICAMP - Universidade Estadual de Campinas por iniciativa do governo estadual eleito em 1982 nas primeiras eleições diretas para governador depois de sua abolição em 1965 pelo governo militar saído do golpe de 1964. Essas eleições de 1982 foram um marco importante da chamada abertura democrática, que resultou no fim da ditadura militar em 1985.

O novo clima político do país motivava uma rediscussão geral de seus rumos, o que incluía amplos debates críticos da educação tecnicista privilegiada pelo regime militar. As propostas curriculares para a rede de ensino paulista faziam parte dessa conjuntura (cf. PALMA FILHO, 1989 e 2005) e serviram de modelo para reformulações semelhantes em vários outros Estados. Seus pressupostos e concepções desaguaram, depois, nos Parâmetros Curriculares Nacionais, decorrentes da LDB de 1996 (lei 9394/96) e, de certa forma, vem orientando a elaboração da BNCC, prevista no PNE - Plano Nacional de Educação (2014-2024). 


\section{VII.}

Vem se tentando, em todos esses anos, difundir e consolidar uma concepção para o ensino de português que busca tirar a gramática do centro das práticas escolares, dando ênfase ao domínio da leitura, da escrita e da oralidade. ${ }^{7}$ Defende-se, então, que o conhecimento gramatical - pensado, não obstante, sob outras coordenadas (como veremos adiante) - seja auxiliar (nunca central) e funcional (isto é, esteja vinculado estreitamente ao domínio da leitura, da escrita e da oralidade). Ou seja, não se descarta totalmente o ensino de natureza gramatical $^{8}$ (afinal, como diz Neves (2002: 226), "produção de texto e gramática não se estranham"), mas se propõe a repensá-lo, subordinando-o e adequando-o aos objetivos maiores do ensino de língua. ${ }^{9}$

Pode-se dizer que são essas as grandes coordenadas que têm articulado o discurso da maioria dos linguistas que se dedicam também a elaborar propostas para o ensino de português. Há, contudo, compreensões diferentes do que deve ser entendido por ensinar gramática, ou, mais especificamente, como se deve conduzir a reflexão sobre a língua.

É consensual entre os linguistas-pedagogos a crítica ao ensino tradicional de gramática centrado na transmissão da nomenclatura e de seus conceitos, seguida de exercícios de mera identificação e classificação de palavras e funções sintáticas. Aponta-se, nessa crítica, a total irrelevância desse saber para o desejável aprimoramento das capacidades de leitura e expressão escrita ou oral. Vai-se, portanto, na direção contrária da arraigada crença da escola e do senso comum que tradicionalmente assevera essa vinculação.

Os linguistas defendem, então, um efetivo deslocamento da questão: deixar de lado a mera transmissão dos conteúdos da gramática tradicional e partir para um trabalho de reflexão sobre as inúmeras possibilidades expressivas que a língua oferece, tendo como objetivo garantir aos alunos as condições para ampliar seu conjunto de recursos expressivos (FRANCHI, 1988/2006: 31); para "operar sobre a linguagem, rever e transformar seus textos, perceber nesse trabalho a riqueza das formas linguísticas disponíveis para suas mais diversas opções” (FRANCHI, 1988/2006: 63-4); para aprender a explorar as várias possibilidades de expressão, a dizer o mesmo de muitas formas (POSSENTI, 1996: 91), alcançando a adequação do dizer tanto aos propósitos comunicativos (eficiência no nível macrotextual) quanto aos padrões socioculturais determinados (atingimento de níveis de desempenho linguístico valorizados na sociedade) -

\footnotetext{
7 Certamente, a versão mais articulada de toda essa tentativa de repensar o ensino de português nas escolas brasileiras se encontra nos trabalhos do linguista João Wanderley Geraldi (cf., em especial, GERALDI 1981, 1991, 1996).

8 Uso a expressão "ensino de natureza gramatical" para dar conta da diversidade e abrangência das propostas feitas pelos linguistas quanto a essa questão específica. O ensino de natureza gramatical não se confunde com o mero ensino de gramática do modo como se faz tradicionalmente. Conforme se verá mais adiante no texto, ele é entendido como uma reflexão ampla sobre os usos e o funcionamento da língua. Nessa concepção, a nomenclatura não é descartada de todo, mas ocupa uma parte pequena do conjunto das atividades didático-pedagógicas. Há também quem defenda que o ensino de natureza gramatical seja um caminho para a prática do pensamento científico tendo a língua como objeto.

9 Apesar disso, é interessante analisar as reações da mídia e dos próprios professores à proposta curricular da década de 1980. Em todas, havia uma grita geral precisamente contra o tratamento dispensado ao estudo da gramática no ensino fundamental. Conforme diz Palma Filho (2005): "Atribuo esse comportamento ao clima criado pela imprensa de São Paulo que, ao não fazer uma leitura atenta da Proposta Curricular, entendeu que os professores não mais deveriam se preocupar com o ensino da gramática”.
} 
(cf. NEVES, 2002: 258); ou, como diz ainda Irandé Antunes (2014: 114), exercitar, no uso, as escolhas possíveis e as escolhas aceitáveis na produção textual-discursiva de sentidos em cada modalidade e gênero. ${ }^{10}$

Penso que se possa dizer que a proposta mais abrangente para dar concretude a essa reconfiguração do ensino de natureza gramatical (entendida essa "natureza gramatical" de modo ampliado para abranger tanto o plano intrassentencial quanto, e principalmente, o plano textual-discursivo) seja a da análise linguística na formulação de João Wanderley Geraldi (1991: 193 e seg.), cujas coordenadas são assim resumidas por Britto (1997: 164): ${ }^{11}$

A análise linguística, que se caracteriza por um debruçar-se sobre os modos de ser da linguagem, ocorre no interior das práticas de leitura e produção. A análise linguística não deve ser entendida como a gramática aplicada ao texto, como supõem os autores de livros didáticos, mas sim como um deslocamento mesmo da reflexão gramatical, e isto por duas razões: em primeiro lugar, porque se trata de buscar ou perceber recursos expressivos e processos de argumentação que se constituem na dinâmica da atividade linguística; em segundo lugar, porque "as gramáticas existentes, enquanto resultado de uma certa reflexão sobre a linguagem são insuficientes para dar conta das muitas reflexões que podemos fazer" (cit. de Geraldi, 1991: 192); finalmente, porque o objetivo fundamental da análise linguística é a construção de conhecimento e não o reconhecimento de estruturas (o reconhecimento só é legítimo na medida em que participa de um processo de construção do conhecimento).

Uma das inspirações para esse deslocamento do ensino de natureza gramatical da mera transmissão de termos e conceitos para a reflexão sobre o funcionamento da língua em uso foi a distinção elaborada por Franchi (1988/2006: 94 e seg.) entre a atividade linguística ("o exercício pleno, circunstanciado, intencionado e com intenções significativas da própria linguagem”; ou, em outros termos, o conjunto de nossas práticas de oralidade, leitura e escrita), a atividade epilinguística (a "prática que opera sobre a própria linguagem, compara expressões, transforma-as, experimenta novos modos de construção canônicos ou não, brinca com a linguagem, investe as formas linguísticas de novas significações"; ou, em outros termos, o conjunto de nossas ações sobre a linguagem sustentadas em reflexões intuitivas sobre o uso e o funcionamento da linguagem) e, por fim, a atividade metalinguística ("um trabalho inteligente de sistematização gramatical", de descrição da "linguagem num quadro nocional intuitivo ou teórico").

Nesse quadro, não se descarta do ensino a atividade metalinguística. Ela fica, porém, deslocada do centro e pressupõe o exercício intenso e extenso de atividades linguísticas e epilinguísticas. Chega-se à atividade metalinguística "como resultado de uma larga familiaridade com os fatos da língua, como decorrente de uma necessidade de sistematizar um "saber" linguístico que se

10 Sílvia Rodrigues Vieira (2017) procurou consolidar esse amplo quadro de referências em três grandes eixos que reproduzimos aqui para auxiliar o balizamento das nossas discussões. Diz ela (2017: 85-6): “Desse modo, é inegável que a escola precisa trabalhar com gramática, (i) considerando o funcionamento de recursos linguísticos em diferentes níveis (fonético-fonológico, morfológico, sintático, semântico-discursivo); (ii) permitindo o acesso às práticas de leitura e produção de textos orais e escritos, de modo a fazer o aluno reconhecer e utilizar os recursos linguísticos como elementos fundamentais à produção de sentidos; e, ainda, (iii) propiciando condições para que o aluno tenha acesso a variedades de prestígio na sociedade, segundo os contínuos de variação (Cf. BORTONIRICARDO, 2005), que configuram uma pluralidade de normas de uso, sem desmerecer outras variedades apresentadas pelo aluno e/ou nos diversos materiais usados".

11 É relevante também consultar o importante texto de Márcia Mendonça (2006) que apresenta em detalhes a análise linguística e a expande. 
aprimorou e que se tornou consciente" (FRANCHI, 1988/2006: 98).

\title{
VIII.
}

Mesmo tendo tudo isso relativamente claro, não se avançou no debate de como enfrentar pedagogicamente a atividade metalinguística. Nesse sentido, algumas questões cruciais continuam sem respostas: que temas merecem sistematização? Em que momento e em que progressão? Que quadros teóricos poderão ser relevantes na organização dessa atividade? Que nomenclatura adotar? Abandonar a NGB ou adotá-la, considerando que ela, a despeito de suas muitas limitações, está naturalizada (cf. BORGES NETO, 2013) na linguística, no discurso escolar e no senso comum? Proceder didaticamente por transmissão ou por descoberta? Em suma, é preciso reconhecer que, apesar de termos clareza conceitual quanto à reconfiguração do ensino de natureza gramatical, há ainda grandes lacunas, em especial quanto à sistematização das propostas para além das asserções gerais.

Os textos que, entre nós, defendem uma abordagem diferente das questões gramaticais no ensino básico raramente vão além de fornecer alguns exemplos do que poderia ser feito.

Há, claro, as exceções. Como já apontamos anteriormente, João Wanderley Geraldi (1984 e 1991) buscou avançar a sistematização, tomando como referência uma certa categorização de problemas que, emergindo em textos de alunos, poderiam orientar as reflexões possíveis, embora reconheça que é "impossível prever todas as atividades de análise linguística que podem ocorrer numa sala de aula" (1991: 193).

Em nota (1991: 241, n. 28), acrescenta comentários ainda hoje válidos quanto às dificuldades concernentes à prática da análise linguística, comentários que vale reproduzir aqui pelos desafios que levantam:

\begin{abstract}
No trabalho desenvolvido com professores, a questão da "análise linguística" é um "calcanhar de Aquiles" no decorrer de todo o trabalho de mudança de perspectiva no ensino. Isto pode ser atribuído: a) à necessidade que sente o professor de um terreno sólido sobre o qual assentar seu ensino; b) à destruição sistemática, na própria formação do professor, de suas intuições de falante que o levam a pensar que ensinar a língua é ensinar a metalinguagem, sustentada em argumentos de autoridade e não em refletir, ainda que intuitivamente, sobre a língua. De qualquer modo, a retomada da questão de um ponto de vista mais escolar é uma necessidade. O problema dessa retomada é que sua leitura a torne um receituário de reflexões a serem feitas, e não uma amostra de reflexões que se fizeram. Enfim, o risco deverá ser assumido em algum momento com a produção de material destinado a professores de $1^{\circ}$ e $2^{\circ}$ graus sobre a análise linguística na sala de aula. Um projeto a mais no horizonte das muitas coisas a fazer.
\end{abstract}

Também Irandé Antunes (2007) tentou (ou, como diz ela à p. 133, correu o risco de) dar passos no sentido de sistematizar um programa com o objetivo de auxiliar os professores a avançar para além da gramática (um programa que "veja a gramática na perspectiva do discurso" - p. 134).

No geral, porém, não tem havido esforços sistematizadores. Os autores não escondem sua expectativa de que os professores, a partir dos poucos exemplos dados, ampliem e expandam por conta própria as propostas. Expressam essa expectativa mesmo reconhecendo que ela é um tanto quanto quimérica nas condições atuais de formação e de trabalho dos professores da nossa escola básica. 
Temos, portanto, em linhas gerais, algumas propostas para o ensino de natureza gramatical. Contudo, parece claro que nos faltam condições para torná-las viáveis. Algumas dessas condições estão fora de nosso alcance direto (como, por exemplo, melhorar as condições de trabalho do magistério); de outras, participamos diretamente (como da formação dos professores, e podemos nos perguntar quanto temos feito para prepará-los efetivamente para a docência, quanto oferecemos a eles possibilidades de ampliação de seus recursos expressivos e possibilidades de efetiva prática de análise científica dos fenômenos linguísticos); por fim, há aquelas para cujo avanço estamos desafiados (como o preenchimento das lacunas das propostas que defendemos) num esforço que não poderá jamais ser apenas individual, mas terá de ser coletivo, envolvendo necessariamente, nesse coletivo, os professores da educação básica.

As lacunas na sistematização têm, claro, seus efeitos: de um lado, dificultam a formação dos professores e, de outro, inviabilizam uma interação produtiva com os professores já em exercício. Uns e outros preferem a segurança do ensino tradicional (mesmo reconhecendo sua ineficácia) porque, bem ou mal, receberam esse ensino em sua própria experiência escolar. Por outro lado, encontram nos livros didáticos o suporte para continuarem reproduzindo a tradição.

\section{IX.}

Ainda quanto ao ensino de natureza gramatical, tem havido, pelo menos desde Perini (1995), uma outra linha propositiva, qual seja, a de fazer do estudo gramatical um exercício de prática científica. Ou, em outras palavras, de dar aos estudos gramaticais na escola básica o estatuto de disciplina científica, contribuindo, desse modo, para a alfabetização científica dos alunos. Em Perini (2016: 56), lemos uma formulação geral dessa proposta:

É minha tese que a gramática pode contribuir para a alfabetização científica se a tratarmos da maneira adequada. E a maneira adequada nos é indicada pelas demais disciplinas científicas: não basta aprender ciência, é essencial também fazer um pouco de ciência. Isso faz da disciplina científica não apenas uma fonte de informações sobre o mundo, mas um campo de treino do pensamento independente, da observação isenta e cuidadosa, do respeito aos fatos - habilidades preciosas, cada vez mais necessárias, mas que brilham pela ausência no ensino tradicional de gramática.

Nessa mesma direção, está o recente livro de Roberta Pires de Oliveira e Sandra Quarezemin - Gramáticas na escola, publicado em 2016. Essas autoras propõem que, no estudo gramatical, seja oferecida aos alunos a oportunidade de desenvolver uma prática de análise científica tendo como objeto fragmentos da(s) língua(s) que falam, construindo, juntamente com seu professor, gramáticas para esses fragmentos.

Não se trata, portanto, de "aprender gramática" ou de "usar a gramática", mas de elaborar gramáticas, ou seja, de construir teorias sobre fatos observados na(s) variedade(s) ou língua(s) dos alunos, aproveitando-se a "intuição que o falante tem sobre a sua língua (i.e., má formação de sentenças e não aceitabilidade, p. ex.)" e seguindo a metodologia das outras ciências empíricas: "formulação de hipóteses a partir dos dados, testes de hipóteses, reformulação de hipóteses e assim por diante" (p. 84).

Essa proposta corre, de certa forma, em paralelo às atividades linguísticas e epilinguísticas. Compreende o ensino de natureza gramatical como uma reflexão de caráter científico que não exclui nem pretende substituir a atividade epilinguística, mas abre uma outra dimensão que é 
vista pelas autoras como importante tanto para a educação científica dos alunos quanto para uma apreensão e compreensão da língua que falamos - um modo de dar visibilidade às suas muitas variedades e, ao desvelar a gramaticalidade de todas elas, de sustentar o combate aos estigmas e preconceitos linguísticos (p. 24). Por fim, reportando-se a experimentos realizados por outros pesquisadores (p. 22), as autoras argumentam que a prática de construção de gramáticas interfere positivamente no desenvolvimento das capacidades de leitura e escrita.

Outros trabalhos recentes têm também apontado nessa mesma direção de se entender o ensino de natureza gramatical como uma espécie de iniciação à atividade científica, mas acrescentam outras balizas para justificar tal ensino na educação básica. É o caso da proposta de Maria José Foltran (2013), que pode ser lida, em boa parte, como um caminho possível para começar a dar concretude à atividade metalinguística prevista por Franchi (1988/2006: 98).

Essa autora entende que "ensinar gramática é operar com os conhecimentos que o falante tem de sua própria língua e torná-los explícitos" (p. 173). Nesse sentido, reconhece que há conhecimentos gramaticais mais prementes e também que os conhecimentos podem se destinar a cumprir objetivos diferentes. Alguns, por exemplo, são essenciais para consultar um dicionário (têm, portanto, uma utilidade prática direta); outros, direcionados a tornar explícito o conhecimento implícito do falante, são importantes para multiplicar as condições de seu uso da língua e, ao mesmo tempo, podem servir como "uma outra forma de a escola introduzir o pensamento científico" (p. 171).

Também aqui - e apesar dos muitos exemplos arrolados (em especial em Oliveira e Quarezemin) - há ainda muito a ser feito no sentido de sistematizar e viabilizar as propostas: Que conhecimentos são mais prementes? Como recortar os fragmentos para o exercício do pensamento científico? Que modelo(s) teórico(s) adotar como referência? E, considerando a atual dispersão dos estudos gramaticais sobre o português brasileiro, que instrumentos linguísticos podem ser usados como referência pelos professores da escola básica? E, na falta deles, como construí-los?

\section{X.}

A todas essas dimensões possíveis do ensino de natureza gramatical que se vem discutindo (algumas já há décadas), se acrescenta um outro elemento complicador. O ensino tradicional da gramática, além de centrado na exposição da nomenclatura estipulada pela NGB e de seus conceitos, seguida de atividades de mero reconhecimento, tem também um viés normativo. Entende-se também que ensinar gramática é ensinar a chamada norma-padrão. Ou, para retomar a concepção vigente desde a Antiguidade, ensinar gramática é também entendido como ensinar a "arte de falar e escrever corretamente"

O senso comum corrente na sociedade e, em consequência, na escola estabelece, como vimos antes, a equivalência entre ensinar português e ensinar gramática; e entende ensinar gramática em dois sentidos: ensinar nomenclatura e ensinar a língua "correta".

Em geral, os linguistas-pedagogos não negam a importância de a escola garantir o domínio $\mathrm{da}(\mathrm{s})$ variedade(s) prestigiada(s) da língua (cf., porém, a interessante discussão sobre esse tema em Bagno, 2017). Ao contrário, entendem que há aí um ganho sociocultural importante do qual não se pode abrir mão. E acreditam que se trata de um objetivo que se alcança por um processo 
de imersão, ou, como diz Possenti (1996: 84), decorre da exposição constante dos alunos ao maior número possível de experiências linguísticas com a(s) variedade(s) prestigiada(s).

Em outras palavras, é a vivência com os autores apropriados, como dizia Comênio, que dará aos alunos as condições de dominar essa(s) variedade(s); é o mergulhar nas práticas da cultura letrada (cf. BRITTO, 1997) que trará, como subproduto, a familiaridade e o progressivo domínio dessa(s) variedade(s). Nesse sentido, parece consensual também o entendimento de que a cultura do erro e as famosas listas dos 100, 400, 1001 "erros mais comuns" não têm qualquer eficácia nesse processo.

Defender o estudo da(s) variedade(s) prestigiada(s) por imersão não significa dizer que não se deva desenvolver paralelamente uma reflexão sobre suas funções sociais no quadro mais amplo da variação linguística e sobre suas características estruturais em contraste com as outras variedades da língua. Também aqui há uma dimensão reflexiva indispensável cujas balizas estão ainda por ser construídas (cf. ZILLES E FARACO, 2015).

Mesmo tendo clareza quanto a esses aspectos, temos, de novo, de reconhecer que, também nessa área, avançamos muito pouco para além das generalidades. Talvez ainda menos do que nas outras dimensões do ensino de natureza gramatical.12

Um dos problemas cruciais aqui é o nosso imbróglio normativo (cf. discussão em Faraco e Vieira, 2016: 302-309). No fundo, como diz Maria Helena de Moura Neves (2002: 239), não temos ainda um padrão razoavelmente definido para o português brasileiro. Continuamos operando sob os ditames da norma-padrão tradicional, que está reduzida, nos livros didáticos, a uma vulgata normativa ou, como a temos designado, a uma norma curta (cf. FARACO, 2008). Não temos encontrado (ou talvez não tenhamos tido a disposição política para encontrar) os caminhos que nos permitam incorporar, nas nossas referências, os fenômenos já consolidados na chamada norma culta brasileira. Apesar da multiplicidade de estudos dialetológicos e sociolinguísticos que vêm desvelando as características do português brasileiro dito culto nas suas modalidades faladas e escritas, não conseguimos ainda resolver minimamente os conflitos entre usos e prescrições. Sem isso, como esperar que a educação básica ofereça aos alunos uma educação linguística de qualidade?

\section{Referências bibliográficas}

Alvará de 30 de setembro de 1770. In: Collecção das Leis, Decretos e Alvarás que comprehende o Feliz Reinado del Rei Fidelíssimo D. José I. Tomo III. Lisboa: Na Off. De Antonio Rodrigues Galhardo, 1801. p. 203-6.

ANTUNES, Irandé. Muito além da gramática: por um ensino de línguas sem pedras no caminho. São Paulo: Parábola Editorial, 2007.

Gramática contextualizada: limpando “o pó das ideias simples”. São Paulo: Parábola Editorial, 2014.

\footnotetext{
12 Apesar do pouco que se avançou nessa área específica, não se pode deixar de mencionar aqui o importante livro organizado por Sílvia Rodrigues Vieira e Sílvia Figueiredo Brandão (2007) que busca, justamente, propor balizas para o enfrentamento didático-pedagógico de conflitos entre prescrições e usos no ensino de português.
} 
BAGNO, Marcos. Gramática, para que te quero? Os conhecimentos linguísticos nos livros didáticos de português. Curitiba: Aymará, 2010.

. Por que estudar uma gramática brasileira? In: CASSEB-GALVÃO, Vânia e NEVES, Maria Helena de Moura (orgs.) O todo da língua: teoria e prática do ensino de português. São Paulo: Parábola, 2017. p. 97-121.

BORGES NETO, José. A naturalização da gramática tradicional e seu uso protocolar. Palestra proferida no VIII Congresso da Abralin, Natal, 2013 (mimeo).

BORTONI-RICARDO, Stella M. Um modelo para a análise sociolinguística do português brasileiro. In: _. . Nós cheguemu na escola, e agora? Sociolinguística e Educação. São Paulo: Parábola Editorial, 2005. p. 45-52.

BRITTO, Luiz Percival L. A sombra do caos: ensino de língua X tradição gramatical. Campinas: ALB e Mercado de Letras, 1997.

CHAPANSKI, Gisele. Uma tradução da Tékhné Grammatiké, de Dionísio Trácio, para o português. Curitiba: Universidade Federal do Paraná, 2003. (Dissertação de Mestrado em Letras) COMÊNIO, Jan. Didactica Magna. Versão digitalizada por eBooksBrasil da edição impressa publicada pela Fundação Calouste Gulbenkian em 2001 com introdução, tradução e notas de Joaquim Ferreira Gomes. Disponível em www.ebooksbrasil.org

FARACO, Carlos Alberto. Norma culta brasileira: desatando alguns nós. São Paulo: Parábola, 2008.

e VIEIRA, Francisco Eduardo. Gramáticas em perspectiva. In: (orgs.) Gramáticas brasileiras, com a palavra os leitores. São Paulo: Parábola, 2016. p. 293-318.

FOLTRAN, Maria José. Ensino de sintaxe: atando as pontas. In: MARTINS, Marco Antônio (org.) Gramática e ensino. Natal: EDUFRN, 2013 .p. 163-83.

FRANCHI, Carlos. Criatividade e gramática (1988). Reprod. em: Mas o que é mesmo "Gramática"? São Paulo: Parábola Editorial, 2006. p. 34-101.

GERALDI, João W. Subsídios metodológicos para o ensino de língua portuguesa no 1o. grau 5a. a 8a. séries. Cadernos Fidene, 18. Ijuí: Fidene, 1981.

. Portos de passagem. São Paulo: Martins Fontes, 1991.

. Unidades básicas do ensino de português (1984). Reprod. em: (org.) $O$ texto na sala de aula. São Paulo: Editora Ática, 1997. p. 57-79.

. Linguagem e ensino: exercícios de militância e divulgação. Campinas: ALB - Mercado de Letras, 1996.

LOBATO, António José dos Reis. Arte da grammatica da lingua portugueza (1770). Estudo, edição crítica, manuscritos e textos subsidiários/ Carlos Assunção. Lisboa: Academia das Ciências, 2000.

MATTOS, Geraldo e BACK, Eurico. Prática de ensino de língua portuguesa. São Paulo: FTD, 1974. 
MENDONÇA, Márcia. Análise linguística no ensino médio: um novo olhar, um outro objeto. In: BUNZEN, Clécio e MENDONÇA, Márcia (orgs.) Português no ensino médio e formação do professor. São Paulo: Parábola, 2006 .p. 199-226.

NEVES, Maria Helena de M. A vertente grega da gramática tradicional. São Paulo: Hucitec Fapesp, 1987.

. Gramática na escola. São Paulo: Contexto, 1990.

- A gramática: história, teoria e análise, ensino. São Paulo: Editora UNESP, 2002.

Que gramática estudar na escola? Norma e uso na língua portuguesa. São Paulo: Contexto, 2006.

OLIVEIRA, Roberta P. de \& QUAREZEMIN, Sandra. Gramáticas na escola. Petrópolis: Vozes, 2016.

PALMA FILHO, João Cardoso. A reforma curricular da SEE/SP para o ensino de 1o. grau (19831987): uma avaliação crítica. . São Paulo: Pontifícia Universidade Católica de São Paulo, 1989. (Dissertação de mestrado em educação)

As mudanças curriculares na década de 1980: uma proposta curricular de língua portuguesa para o ensino fundamental. Anais do 15o. COLE. Disponível na página da Associação Brasileira de Leitura (alb.com.br).

PEREIRA, Marcos A. Quintiliano gramático: o papel do mestre de gramática na Institutio oratoria. 2aed. São Paulo: Associação Editorial Humanitas, 2005.

PERINI, Mário A. Gramática descritiva do português. São Paulo: Editora Ática, 1995.

Gramática descritiva do português brasileiro. Petrópolis: Vozes, 2016.

POSSENTI, Sírio. Por que (não) ensinar gramática na escola. Campinas: ALB - Mercado de Letras, 1996.

QUINTILIANO, Marco F. Instituição oratória. Trad. De Bruno F. Bassetto. Campinas: Editora da UNICAMP, 2015-2016.

RAZZINI, Marcia de Paula G. O espelho da nação: a Antologia Nacional e o ensino de português e literatura (1883-1971).Campinas: UNICAMP, 2000. (Tese de doutorado em Letras)

The Jesuit Ratio Studiorum of 1599. Washington: Conference of Major Superiors of Jesuits, 1970. Disponível em www.bc.edu/sites/libraries/ratio/ratio1599.pdf

VIEIRA, Francisco Eduardo. Gramáticas brasileiras contemporâneas do português: movimentos de ruptura e linhas de continuidade com o paradigma tradicional de gramatização. . Recife: Universidade Federal de Pernambuco, 2015. (Tese de doutorado em Letras)

Gramatização brasileira contemporânea do português: novos paradigmas? In: FARACO, Carlos A. e VIEIRA, Francisco Eduardo (orgs.) Gramáticas brasileiras: com a palavras, os leitores. São Paulo: Parábola Editorial, 2016. p. 19-69.

VIEIRA, Sílvia R. Três eixos para o ensino de gramática: uma proposta experimental. In: NORONHA, Claudianny A. e SÁ JR., Lucrécio A. de (orgs.) Escola, ensino e linguagem [recurso eletrônico]. Natal: EDUFRN, 2017. p. 78-104. 
e BRANDÃO, Sílvia F. (orgs.) Ensino de gramática: descrição e usos. São Paulo: Contexto, 2007.

ZILLES, Ana Maria S. e FARACO, Carlos Alberto (orgs.) Pedagogia da variação linguística: língua, diversidade e ensino. São Paulo: Parábola, 2015.

Recebido: 12/2017

Aceito: 12/2017 